The Sustainable City XIII 331

\title{
ECOLOGICAL VALUE OF ABANDONED WILD LANDSCAPES IN CHINESE CITIES
}

\author{
XINLEI HU \& MARIA FRANCISCA LIMA \\ Edinburgh School of Architecture and Landscape Architecture, The University of Edinburgh, UK
}

\begin{abstract}
This paper is focused on urban industrial abandoned wild landscapes which have experienced structural changes, and where abandonment triggered a natural vegetation succession process, as well as fauna's progressive reoccupation. Due to such natural regeneration, abandoned wild landscapes have high biodiversity and ecological value and have been gaining attention from the scientific and planning communities. In the Chinese context, abandoned wild landscapes are frequently contested and subsumed into various utilitarian discourses regarding redevelopment or erasure, leading to an underestimation of their ecological value in urban contexts. Through reviewing academic literature, this paper explores abandoned wild landscapes in terms of the ecological value they encompass and related benefits for both sustainable urban development and ecological pressure. Moreover, this study also presents an overview of the causes of abandoned wild landscapes in different world contexts and analyses their controversy in China. The paper concludes by advocating that abandoned wild landscapes do have ecological values worthy of further understanding and appreciation, due to their potentially vital role in the ecosystems of contemporary Chinese cities.
\end{abstract}

Keywords: wasteland, ecological value, biodiversity, spontaneous vegetation, Chinese cities.

\section{INTRODUCTION}

Habitats evolved in urban industrial wastelands, which we call abandoned wild landscapes in this paper, are unintentional products of abandonment and natural succession [1]. Flora and fauna can settle spontaneously in industrial wastelands without human interferences. Frequently, these spaces are perceived as useless, blight places without intrinsic values [2]. A counter-discourse has emerged in recent years in terms of re-evaluation of abandoned wild landscapes from the ecological perspective. Along with urban ecology development, especially in Europe, a group of ecologists demonstrate that naturally regenerated urban wastelands have high biodiversity levels [3], [4], which contributes to their high ecological value [5]. As "ecological refugia" or "islands of biodiversity" [6], abandoned wild landscapes have appeared in discourses of nature conservation and urban green infrastructure as well [6]-[9].

In China, most abandoned wild landscapes are viewed only from their utilitarian potentialities [10], [11]. Most of them have been eradicated for residential and commercial uses or redeveloped as artificial parks for Chinese "urban beautification" [11]. Under such a background, abandoned wild landscapes are not very well examined in respect of their ecological value. However, abandoned wild landscapes do have ecological value and play a certain role for the ecological functionality in cities. They could provide more ecological benefits to cities if managed appropriately [12].

Based upon this insufficient understanding of abandoned wild landscapes in the Chinese context, a review of literature is then brought to raise the awareness of the ecological value abandoned wild landscapes harbour and to advocate a deeper understanding of this landscape type. Re-imaging abandoned wild landscapes allows not only better strategies for these spaces' future development but also promotions of their role in Chinese cities facing ecological pressure. 


\section{THE EMERGENCE OF ABANDONED WILD LANDSCAPES}

The source of abandoned wild landscapes is industrial wasteland - post-industrial sites that have been abandoned [5]. Driving forces triggering the generation of industrial wastelands are various in different socio-political contexts. European's depopulation process [13], [14] and economic structural changes in respect of de-industrialisation [15] and companies' relocation have led to factories' closure and site abandonment [5]. In America, a variety of urban processes regarding urban sprawl, de-industrialisation, decentralisation, and depopulation have caused a rise of waste spaces, including industrial wasteland in cities [12], [16], [17].

In China, heavy industry decline and relocation are mainly caused by policy actions [18] and urban sprawl [19], [20]. According to the environmental policy concerning urban pollution problem, China's heavy industry enterprises have been forced to relocate to other regions or cities [18]. Beijing has experienced several waves of industrial land use change. The most recent one was the relocation of large industrial enterprises on the eve of the Beijing Olympics in 2008 for responding environmental quality management plan of this sports activity [18]. China's industrial wastelands are also the spatial by-product of unprecedented urban sprawl [19], [20]. With cities' rapid expansion, much land within built-up areas is abandoned or insufficiently used. Furthermore, with the implementation of economic reform policy since 1978, China has entered a stage of rapid urbanisation and industrial transformation [21]. In this process, most traditional and heavy industries have declined [22]. Policies such as "Suppress Second Industry and Develop Tertiary Industry" have contributed to the closure or relocation of old factories and industries [18], [22]. Shenzhen, the manufacturing centre in South China, is now experiencing de-industrialisation with around $30-45 \%$ factories vacant in 2013 [23]. Old industrial northeast cities dependent on extracting resources like coal and oil have difficulties in adapting this transformation process. Despite generous financial support provided by the central government, these cities have failed to revive, facing factories closure, land vacancy, population loss and other socio-economic problems [24].

\section{PERCEPTIONS OF ABANDONED WILD LANDSCAPES}

\subsection{Negative perceptions}

Frequently urban wastelands and voids are assumed with no intrinsic values because they have no clear and formal functions, and may harbour pollution, trash, or illegal activities [1]. Girot [25], a French landscape architect, describes them as "landscapes of contempt". Moreover, for a long time, vegetation on wastelands was visualized as "biological slumming" [26] or "negative habitats" [27].

Land abandonment, as well as the ruination of buildings, implies moral deficiencies, destruction, and misfortune in both Western and Chinese cultures from an early period [28][30]. Ruins are often used in visual arts or literature to represent the link to past civilizations [31], but frequently, they are the symbol of death, decay, and man's futile efforts [13], [28], [32]. In traditional Chinese culture, portraying ruins is a taboo because it means inauspiciousness and danger [33]. Moreover, compared to feelings of awe evoked by ancient ruins, urban ruins in the postmodern period are new, ubiquitous, and are associated closely with urban decline, war or natural catastrophe [13], [28], [32].

The term "wasteland", which commonly refers to post-industrial abandoned sites today, has a contested cultural history that is fundamental in shaping people's attitudes toward land regarding uselessness and usefulness [34]. According to Di Palma [34], wastelands in 
Biblical texts represent remote, desolate places where Christ and the hermit saints being exiled and tested with physical and emotional difficulties. In English landscapes from 17th to 18 th century, wastelands referred to swamps, mountains, and forests. Today, wastelands denote abandoned, derelict post-industrial spaces commonly. In every period, "wasteland" is always used to describe sites that resist notions of appropriate use in relation to domestication [34]. Therefore, wastelands call for improvement and cultivation. In the 17th century, there were improvements to drain swamps and transform them into fields for agriculture [34]. Today's wastelands are seen to be useless spaces without clear and formal functions, and therefore they are shown as blankness in maps or plans [2], [35], [36]. In China, one of the most important issues in the Urban Master Plan, from the central to the local governments, is urban renewal [37], namely, transforming wastelands into spaces with formal uses. Projects in China like Houtan Wetland Park and Zhongshan Shipyard Park respond to this renewal trend, showing how industrial wastelands might be redeveloped into places of leisure and recreation.

\subsection{Ecological re-evaluation}

An alternative sensibility that counters negative perspectives has made abandoned wild landscapes become a focus for ecological and environmental attention. The emergence of ecological insights regarding these spaces is not so new since it can be traced back to European scientists' early studies of urban wild flora in the 17th century [38]. Nevertheless, the independent research regarding ecological status of wasteland habitats was only established by the development of urban ecology in the 1970s in Europe [5], [39].

It is acknowledged that abandoned wild landscapes have a high species diversity level and accommodate rare, endangered species with many Red Data species [5], [7], [40]-[42]. Muratet et al. [43] found in the Hauts-de-Seine département, a place near Paris, the abundance of vegetation varieties of wasteland accounted for $58 \%$ of the entire region. Harvie [44] indicated that West Lothian's oil-shale bings, the production of oil exploitation abandonment in Edinburgh, accommodated more than $44 \%$ of this entire region's species. Rare species like lichens [45], mosses and liverworts [46] from Red Data Books of Britain and Ireland have been located there. Oil-shale bings also function as refugees for a variety of insects and birds.

Abandoned wild landscapes harbour high species diversity [5], [40], which contributes profoundly to their ecological and biodiversity value. In the UK, many local government documents such as Biodiversity Action Plan recognise wastelands ecological value and tend to use the term "open mosaic habitat" to replace terms like "brownfield" or "wasteland" [44], [47]. As Sukopp [48], an influential figure in wasteland ecosystem studies points out,

"[Wastelands]... have very high diversity [and] large connected vacant sites are particularly outstanding habitats, ranging from pioneer stages, in heavily disturbed areas, to pre-forest stages in others" [48, p. 41].

Abandoned wild landscapes have been suggested as a part of urban green infrastructure system. These landscapes provide ecosystem services from habitats for wildlife, soil building, to flood control, carbon sequestration and storage, and temperature reduction [6], [7], [9], [49], [50]. Del Tredici [7] suggests ecosystem services provided by spontaneous vegetation on abandoned land might be more important in the future, given the impact of urbanisation, globalisation, and climate change that makes the vast majority of urban vegetation a cosmopolitan assemblage. 
Ecological studies of abandoned wild landscapes contribute to a better understanding and appreciation of these once condemned places. Kowarik, an ecologist in Berlin, considers spontaneous nature settlements on previously industrial land as a type of urban nature, with his articulation as "new wilderness" [39] based upon the previous work of Dettmar et al. [51]. "The four natures approach" is proposed by him to categorise space types that can supply wild nature in urban and peri-urban areas (Table 1) [52]. "New wilderness" is an independent category known as Nature 4, a novel urban ecosystem. This approach shows the recognition of the ecological value of abandoned wild landscapes and suggests there is no privilege or superiority among different urban nature types. Ward Thompson [53] articulates ecological opportunities provided by "loose-fit landscapes" on derelict and waste lots. She addresses the importance of informal green spaces [54] in urban open space networks for encouraging the natural cyclical system in terms of growth and decay. Abandoned wild landscapes represent a counterpoint to controlled and designated urban spaces and offer opportunities that cannot be provided by formal urban spaces, such as providing a wilder natural place for teenagers to contact with nature [53].

Table 1: Four natures approach [4].

\begin{tabular}{|l|l|l|}
\hline Types of "nature" & Types of ecosystems & Examples \\
\hline $\begin{array}{l}\text { Nature 1: } \\
\text { "old wilderness" }\end{array}$ & Pristine ecosystems & Remnants of pristine forests \\
\hline $\begin{array}{l}\text { Nature 2: } \\
\text { "traditional cultural landscape" }\end{array}$ & $\begin{array}{l}\text { Ecosystems shaped by } \\
\text { silvi/agriculture }\end{array}$ & $\begin{array}{l}\text { Forests strongly } \\
\text { characterized by silviculture }\end{array}$ \\
\hline $\begin{array}{l}\text { Nature 3: } \\
\text { "functional greening" }\end{array}$ & $\begin{array}{l}\text { Ecosystems } \\
\text { established by urban } \\
\text { greening }\end{array}$ & $\begin{array}{l}\text { Planted tree stands in green } \\
\text { spaces }\end{array}$ \\
\hline $\begin{array}{l}\text { Nature 4: } \\
\text { "new wilderness" }\end{array}$ & $\begin{array}{l}\text { Ecosystems evolved } \\
\text { on urban-industrial } \\
\text { sites }\end{array}$ & $\begin{array}{l}\text { Woodland succession on } \\
\text { urban-industrial sites }\end{array}$ \\
\hline
\end{tabular}

\section{THE CONTROVERSY OF ABANDONED WILD LANDSCAPES IN CHINA}

In contrast to efforts in ecological studies of abandoned wild landscapes in Europe, and European scholars' openness to accept and subsume them into nature conservation and urban green infrastructure discourses, these spaces in China are frequently discussed by authorities in terms of their utilitarian potentialities [10], [11], although a group of scholars have suggested their ecological value for conserving [10], [11], [55]-[58].

When abandoned wild landscapes are incorporated into utilitarian discussions, their ecological value tends to be ignored. China's rapid urbanisation is mainly reflected in the increase of developed and built land, which indicates that the income from the land transformation process could contribute to a major part of governments' financial revenue [19]. Many land developers also engage in this rebuilt process to make more profits through land use rights trading [37]. Therefore, these ostensibly unproductive, undeveloped wild brownfields have been included in urban renewal discussion to fulfil urban development needs [11]. Furthermore, not all Chinese people assess abandoned wild landscapes positively [59]. Wild nature aesthetics can be found in a Western cultural context, but may not in a Chinese cultural context, where people tend to appreciate a place shaped by high civilisation and culture with human touch and care [59], [60].

However, abandoned wild landscapes do encompass valuable ecological qualities that are worthy of understanding, especially for Chinese cities that are experiencing rapid 
urbanisation [61] and at the very same time, loss of natural habitats and biodiversity [62][65]. $15 \%$ to $20 \%$ of China's species are endangered [63]; genetic resources have declined dramatically in the past 60 years, and 233 vertebrate species are at risk of extinction [65]. Furthermore, China's species conservation policies and management have barriers at present because the most threatened wild species such as wild plant species with extremely small populations (PSESP) do not receive the conservation priority, and little attention has been forthcoming from authorities [66]. In this sense, recognising the biodiversity and high rare species populations in abandoned wild landscapes instead of perceiving them from the economic perspective could enhance our appreciation of them and therefore, manage them properly as a natural asset for Chinese biodiversity conservation.

\section{THE ECOLOGICAL VALUE OF ABANDONED WILD LANDSCAPES IN CHINA} In recent years, a group of Chinese scholars have started to show awareness and recognition to urban wastelands ecology and assert their ecological value [10], [11], [55]-[58]. Wang [67], [68], a professor at Beijing Forestry University, along with Wang and Wang [11] and Wang [57], recognise the ecological value of landscapes driven by natural process on urban wastelands and articulate how these landscapes are favourable in terms of low-maintenance efforts. Han and $\mathrm{Li} \mathrm{[10]}$ propose the idea of "urban remnant seminatural habitat" to refer to natural habitats remained in urban built-up zones and marginal spaces, including those developed naturally on artificial areas without human interference now. They also suggest that facing greater urbanisation and urban renewal pressure in Chinese cities, it is an important work to conduct systematic surveys and evaluations of marginal habitats and incorporate them into Urban Master Plan for sustainable conservation and management. Gong [55] and Zheng [58], use the concept of "urban remnant natural area" - natural or nearnatural and historical habitats undisturbed by people in the city, including habitats evolved on derelict historical industrial areas - to conduct several empirical studies of abandoned wild landscape sites in Shanghai, and examine these spaces' diverse values with the establishment of evaluation systems. Studies of Jin et al. [69], and Chen and He [70] address how industrial natural forests in Ruhr as an approach, can provide helpful experience for Chinese brownfields' management under a small governmental capital input and low human maintenance efforts. However, most research above explores a broader idea of urban natural habitats that subsumes the remnant pristine or agrarian landscapes in cities, and abandoned wild landscapes are only a small part of this broader idea. Therefore, the ecological value recognition may not specific and targeted to abandoned wild landscapes' particular characteristics and might not be comparable to systematic and targeted urban wasteland ecology studies of Sukopp [3], [48], Kowarik [4], [41], [42], Del Tredici [7], [71], etc.

Following on Chinese studies of urban wasteland ecology mentioned above, two case studies - abandoned mining area in Xuzhou and abandoned Jiangwan Airport in Shanghai are presented to examine their specific ecological characteristics and value in the context of China.

\subsection{Case 1: Abandoned mining area in Xuzhou}

Ecological studies of abandoned mining areas in Xuzhou reveal the dereliction of urban mining land can evolve into a wetland ecosystem spontaneously [72]-[74]. Xuzhou is an important coal city in the eastern plain of China. In Xuzhou metropolitan area, 29 coal mining sites were abandoned by 2012 [73]. Because of the high groundwater level in Xuzhou, after extensive mining exploitation and disposal, the ground surface begins to collapse, and subside into a basin where water accumulates quickly [72], [75]-[77]. 
Collapsed ground and water accumulation are distinct features of these post-industrial waste places, which in turn promotes the formation of wetlands with spontaneous vegetation in these areas after abandonment. Two unused sites have been redeveloped as wetland parks, whereas others waiting for an uncertain future. Interestingly, social appropriation has occurred. Some residents occupy these sites spontaneously for fishing or feeding waterfowl [77].

The ecological value of these places is high, creating amphibious urban wetland ecosystems [72]. They accommodate a wide range of valuable plant and animal species, including woodpeckers, red-rumped swallow (Cecropis daurica), brown shrike (Lanius cristatus), reeds, and cattails [72]. Apart from the ecosystem service like urban habitats for plants and wildlife, these wetlands also play an important role in regulating climate and absorbing the remnant coal contamination.

One abandoned site - North Lake Marsh Wetland - in Jiulihu district is an experimental area of natural restoration in abandoned coal gangue field in Xuzhou (Fig. 1). The area is restoring itself by the power of nature after subsiding steadily along with the overgrowth of spontaneous vegetation and biodiversity [74]. According to our field trip, it is a home for a wide range of birds. Most bird species are listed in the national document List of Terrestrial Wildlife that are Beneficial to the State or have Important Economic and Scientific Value, published by the State Forestry Administration. One species - Anser cygnoides - is included in the IUCN Red List of Threatened Species 2016, and being assessed as vulnerable [78]. Interestingly, Yang's study [74] found that the public in Xuzhou deemed North Lake Marsh Wetland had higher ecological value compared with an artificial wetland park nearby. However, people's overall evaluation of artificial wetland park is better than North Lake Marsh Wetland.
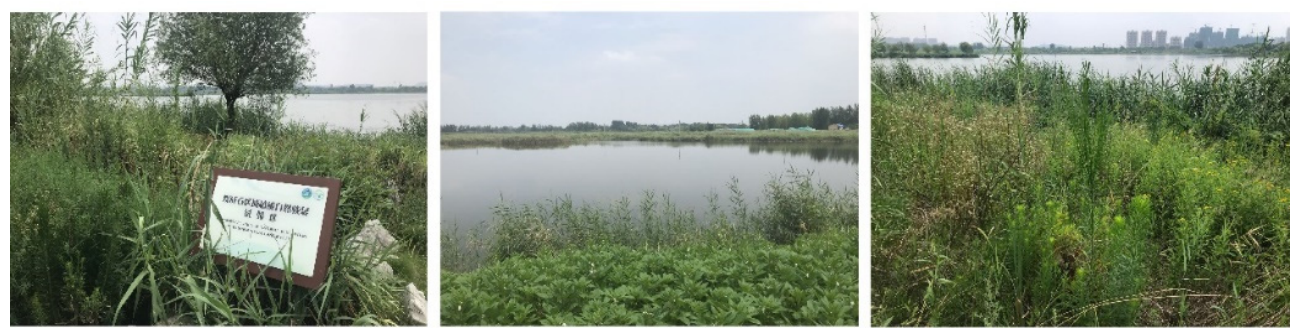

Figure 1: North Lake Marsh Wetland in Xuzhou. (Source: Authors.)

\subsection{Case 2: Abandoned Jiangwan Airport in Shanghai}

Chinese scholars' ecological research of Shanghai's abandoned Jiangwan Airport [55], [58], [79]-[81] confirm European scholars ecological recognition regarding urban wastelands and urban industrial woodlands. Initially, Jiangwan was a typical Yangtze delta wetland with a network of rivers and ponds until the early period of Republic of China in the 1920s [80]. With population growth in the region during that period, the original Yangtze delta wetland landscape has been changed to some degree. After the construction of a military airport here in 1939, the surface water was forced to enter the underground drainage system, leaving original rivers disappeared with only one river remnant [58].

After being abandoned in 1989, natural succession has occurred in this airport because of low human interference. After 1994, most buildings and some aeroplane concrete runways 
within the airport were demolished. As the underground drainage system was damaged, lowlying land was gradually restored to ponds and floodplains naturally. Most spaces within this area have become secondary swamps and seasonal wetlands [80].

Three natural habitats within abandoned Jiangwan Airport were located: woodland and shrub habitat, herb habitat, and wetland habitat [80]. According to the ecological study conducted by Jin et al. [80] from 2001 to 2003, Shanghai's native species like hackberries, paper-mulberries, silvergrass, and reeds were growing there. China's rare and endangered species such as Glycine soja, Viverricula indica, were found along with various butterfly species. A large area of woodland and shrub habitat, known as Great Green Island, was almost entirely covered by natural plants [55], [58], [80]. Cui et al. [79] found summer avian communities' diversity in Great Green Island was higher than that in Pudong Centre Park, Xisheshan National Forest Park, and in Dajinshan Island Natural Reserve. In the natural vegetation species composition of abandoned Jiangwan Airport, the proportion of herbaceous plants reached $82.6 \%$ with high populations of cosmopolitan species [81]. Abandoned Jiangwan Airport is suggested to reflect the constantly changing urban land use in Shanghai, from initial Yangtze delta wetland to agriculture land in the period of Republic of China, to industry airport from the 1930 s to 1990 s, to a wasteland habitat in the 21 st century.

However, being included in New Jiangwan City Plan, parts of abandoned Jiangwan Airport have been replaced by residential and commercial districts, despite all the efforts made by various groups to protect this natural habitat. The natural wasteland in the east part remains undeveloped (Fig. 2).

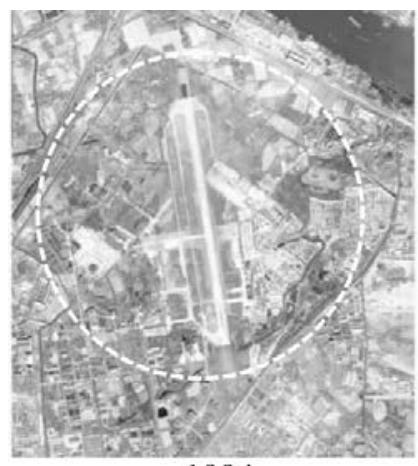

1994

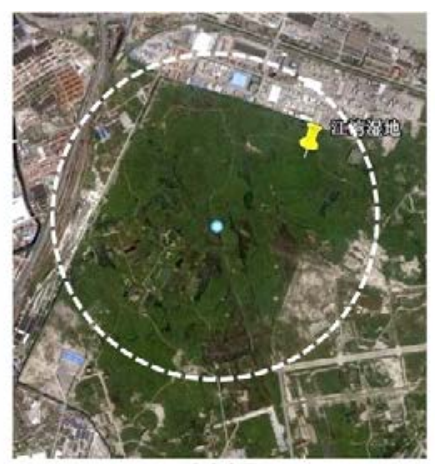

2007

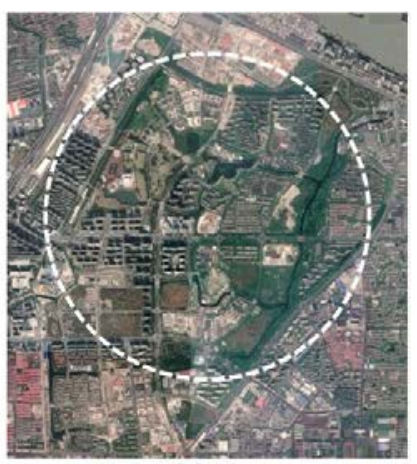

2019

Figure 2: Abandoned Jiangwan Airport in 1994, 2007, 2019. (Source: Jin et al. [80]; Oriental Morning Post [82]; authors.)

\section{CONCLUSION}

Based upon Western and Chinese literature, this paper has shown additional knowledge to a landscape type that is perceived maligned commonly - abandoned wild landscapes, namely, urban industrial wastelands with spontaneous vegetation and wildlife, by analysing their ecological value and related ecological benefits for Chinese cities. The paper presents causes of abandoned wild landscapes in different world contexts and examines commonly negative attitudes toward them. An alternative ecological insight regarding abandoned wild landscapes as an ecologically rich natural habitat for conservation has brought into the discussion through, which contrasts and challenges previous perceptions of abandoned wild landscapes as spaces with no intrinsic values. 
It is reasonable to reconsider the ecological value in abandoned wild landscapes in China in the context of rapid urbanisation and also, the biodiversity and natural habitat loss. The requirement of urbanisation and economic development make Chinese attention tends to focus on their redevelopment potentials while ignoring their ecological value. Using two cases in Xuzhou and Shanghai and related Chinese and Western literature, this paper demonstrates that abandoned wild landscapes do have ecological value and illustrates ecological benefits that they can bring to Chinese cites as well as how they can be better understood and appreciated.

The biodiversity and a high number of rare species in two cases confirm Western scholars' findings. More importantly, abandoned wild landscapes provide a series of ecosystem services such as habitats for wildlife, water purification, and mitigation of the urban heat island effect for rapid developing Chinese cities facing environmental problems and ecological pressure. From the ecological functional level, abandoned wild landscapes create sustainable ecosystems in a way that they are offering impressive ecosystem services with the minimum of maintenance input. Capturing and understanding their ecological value could influence Chinese perceptions of them and lead to a better appreciation. Therefore, what we need to concern regarding these spaces is not redevelopment or eradication, but rather sustainable conservation and management.

\section{ACKNOWLEDGEMENTS}

We would like to thank Mr Ross McLean for his comments and insights. Thanks also to Professor Catharine Ward Thompson and OPENspace Research Centre, Edinburgh School of Architecture and Landscape Architecture, The University of Edinburgh.

\section{REFERENCES}

[1] Anderson, K.M., Marginal Nature: Urban Wastelands and the Geography of Nature, The University of Texas at Austin, 2009.

[2] Jorgensen, A., Introduction. Urban Wildscapes, eds A. Jorgensen \& R. Keenan, Routledge: London, pp. 1-14, 2012

[3] Sukopp, H., The soil, flora, and vegetation of Berlin's waste lands. Nature in Cities: The Natural Environment in the Design and Development of Urban Green Space, ed. I.C. Laurie, 1979. https://books.google.co.uk/books?id=tzLVtgAACAAJ.

[4] Kowarik, I., Wild urban woodlands: Towards a conceptual framework. Wild Urban Woodlands: New Perspectives for Urban Forestry, Springer: Berlin, Heidelberg, pp. 1-32, 2005.

[5] Rink, D. \& Herbst, H., From wasteland to wilderness: Aspects of a new form of urban nature. Applied Urban Ecology: A Global Framework, pp. 82-92, 2011.

[6] Gandy, M., Marginalia: Aesthetics, ecology, and urban wastelands. Annals of the Association of American Geographers, 103(6), pp. 1301-1316, 2013.

[7] Del Tredici, P., Spontaneous urban vegetation: Reflections of change in a globalized world. Nature and Culture, 5(3), pp. 299-315, 2010.

$\mathrm{http} / / /$ berghahnjournals.com/view/journals/nature-and-culture/5/3/nc050305.xml.

[8] Kowarik, I., Fischer, L.K., Säumel, I., von der Lippe, M., Weber, F. \& Westermann, J.R., Plants in urban settings: From patterns to mechanisms and ecosystem services. Perspectives in Urban Ecology: Ecosystems and Interactions between Humans and Nature in the Metropolis of Berlin, ed. W. Endlicher, Springer: Berlin, Heidelberg, pp. 135-166, 2011. DOI: 10.1007/978-3-642-17731-6_5. 
[9] Rink, D., Wilderness: The nature of urban shrinkage? The debate on urban restructuring and restoration in Eastern Germany. Nature + Culture, 4(3), pp. 275292, 2009. http://search.proquest.com/docview/214141889/.

[10] Han, X. \& Li, D., Progress in the study on urban remnant seminatural habitats. Journal of Natural Resources, 24(4), pp. 561-566, 2009. (In Chinese.)

[11] Wang, X. \& Wang, X., Urban wilderness based on the view of landscape architecture. Chinese Landscape Architecture, 8, pp. 40-47, 2017. (In Chinese.)

[12] Kim, G., The public value of urban vacant land: Social responses and ecological value. Sustainability, 8(5), pp. 1-19, 2016.

[13] Lima, M.F., The Role of Open Spaces in Depopulated Urban Environments, The University of Edinburgh, 2016.

[14] Lima, M.F. \& Eischeid, M.R., Shrinking cities: Rethinking landscape in depopulating urban contexts. Landscape Research, 42(7), pp. 691-698, 2017.

DOI: $10.1080 / 01426397.2017 .1372167$.

[15] Rink, D. \& Emmrich, R., Surrogate nature or wilderness? Social perceptions and notions of nature in an urban context. Wild Urban Woodlands: New Perspectives for Urban Forestry, eds I. Kowarik \& S. Korner, Springer: Berlin, Heidelberg, pp. 67-80, 2005.

[16] Berger, A., Drosscape: Wasting Land in Urban America, Princeton Architectural Press: New York, 2006.

[17] Bowman, A.O. \& Pagano, M.A., Terra Incognita: Vacant Land and Urban Strategies, Georgetown University Press: Washington, DC, 2004.

[18] Zheng, X., Landscape research on brownfield regeneration: "Brown earth-work" to bridge environmental remediation and landscape design. Chinese Landscape Architecture, 31(4), pp. 10-15, 2015. (In Chinese.)

[19] Bai, X., Chen, J. \& Shi, P., Landscape urbanization and economic growth in China: Positive feedbacks and sustainability dilemmas. Environmental Science and Technology, 46(1), p. 132, 2012.

[20] Zhou, W., Jiao, M., Yu, W. \& Wang, J., Urban sprawl in a megaregion: A multiple spatial and temporal perspective. Ecological Indicators, 96, p. 54, 2019.

[21] Yang, J. \& Luo, C., Renewal and redevelopment of old industrial areas in the postindustrial period. City Planning Review, 35(4), pp. 80-84, 2011. (In Chinese.)

[22] Wang, J. \& Jiang, N., Protective reuse of China's industrial historical buildings in the post-industrial era. Architectural Journal, 8, pp. 8-11, 2006. (In Chinese.)

[23] Zou, M., Transforming the "World Factory": Designing for a [Post]Industrial Shenzhen, Massachusetts Institute of Technology, 2014. http://dspace.mit.edu/handle/1721.1/91426

[24] Li, H. \& Mykhnenko, V., Urban shrinkage with Chinese characteristics. Geographical Journal, 184(4), pp. 398-412, 2018.

[25] Girot, C., Vers une nouvelle nature. Trans-scape, Zurich: Department of Architecture, ETH publication, 11, pp. 40-45, 2004.

[26] Mabey, R., Unofficial Countryside, Pimlico, 1999. https://books.google.co.uk/books?id=3q8WcAAACAAJ.

[27] Keil, A., Industriebrachen Innerstädtische Freiräume für die Bevölkerung. Mikrogeografische Studien zur Ermittlung der Nutzung und Wahrnehmung der neuen Industrienatur in der Emscherregion, Dortmunder Vertrieb fur Bau- und Planungsliteratur: Dortmund, 2002. (In German.)

[28] Jorgensen, A. \& Tylecote, M., Ambivalent landscapes: Wilderness in the urban interstices. Landscape Research, 32(4), pp. 443-462, 2007. 
[29] Meserve, R.I., The inhospitable land of the barbarian. Journal of Asian History, 16(1), pp. 51-89, 1982.

[30] Williams, D.M., The barbed walls of China: A contemporary grassland drama. Journal of Asian Studies, 55(3), pp. 665-691, 1996.

[31] Woodward, C., Learning from detroit or "the wrong kind of ruins". Urban Wildscapes, eds A. Jorgensen \& R. Keenan, Taylor and Francis: London, pp. 17-32, 2012.

[32] Lyons, C., Archives in ruins. Irresistable Decay: Ruins Reclaimed, eds M. Roth, C. Lyons \& C. Merewether, Getty Research Institute for the History of Arts and Humanities: Los Angeles, pp. 80-85, 1997.

[33] Wu, H., Ruins, fragmentation, and the Chinese modern/postmodern. Inside Out: New Chinese Art, ed. M. Gao, San Francisco Museum of Modern Art: San Francisco, New York, Berkeley, pp. 59-66, 1998.

[34] Di Palma, V., Wasteland: A History, Yale University Press: New Haven, 2014.

[35] Doron, G.M., The dead zone and the architecture of transgression, City, 4(2), pp. 247263, 2000. www.tandfonline.com/doi/full/10.1080/13604810050147857.

[36] Unt, A.L., Travlou, P. \& Bell, S., Blank space: Exploring the sublime qualities of urban wilderness at the former fishing harbour in Tallinn, Estonia. Landscape Research, 39(3), pp. 267-286, 2014.

[37] Li, W., Zhou, W., Bai, Y., Pickett, S.T.A. \& Han, L., The smart growth of Chinese cities: Opportunities offered by vacant land. Land Degradation and Development, 29, pp. 3512-3520, 2018.

[38] Tournefort, P., Histoire des plantes qui naissent aux environs de Paris, avec leur usage dans la Medecine, Paris de l'imprimaire Royale: Paris, 1698. (In French.)

[39] Kowarik, I. \& Korner, S., Wild Urban Woodlands New Perspectives for Urban Forestry, eds I. Kowarik \& S. Korner, Springer: Berlin, 2005.

[40] Bonthoux, S., Brun, M., Di, F., Greulich, S. \& Bouché-Pillon, S., How can wastelands promote biodiversity in cities? A review. Landscape Urban Planning, 132, pp. 79-88, 2014. DOI: 10.1016/j.landurbplan.2014.08.010.

[41] Kowarik, I., Novel urban ecosystems, biodiversity, and conservation. Environmental Pollution, 159, pp. 1974-1983, 2011. DOI: 10.1016/j.envpol.2011.02.022.

[42] Kowarik, I., Urban wilderness: Supply, demand, and access. Urban Forestry and Urban Greening, 29, pp. 336-347, 2017.

[43] Muratet, A., Machon, N., Jiguet, F., Moret, J. \& Porcher, E., The role of urban structures in the distribution of wasteland flora in the greater Paris area, France. Ecosystems, 10(4), pp. 661-671, 2007.

[44] Harvie, B., West Lothian Local Biodiversity Action Plan Oil Shale Bings, 2005.

[45] Church, J.M., Coppins, B.J., Gilbert, O.L., James, P.W. \& Stewart, N.F., Red Data Books of Britain and Ireland: Lichens, Joint Nature Conservation Committee: Peterborough, 1996.

[46] Church, J.M., Hodgetts, N.G., Preston, C.D. \& N.F.S., Red Data Book for Britain and Ireland: Mosses and Liverworts. Joint Nature Conservation Committee: Peterborough, 2001.

[47] Buglife, Planning for Brownfield Biodiversity: A Best Practice Guide, 2009. www.buglife.org.uk.

[48] Sukopp, H., Development of Flora and Fauna in Urban Areas, Council of Europe: Strasbourg, 1987.

[49] Kowarik, I, Fischer, L.K., Säumel, I., Von Der Lippe, M., Weber, F. \& Westermann, J.R., Plants in urban settings: From patterns to mechanisms and ecosystem services. Perspectives in Urban Ecology: Ecosystems and Interactions between Humans and 
Nature in the Metropolis of Berlin, ed. W. Endlicher, Springer: Berlin, Heidelberg, pp. 135-166, 2011.

[50] Savard, J.-P.L., Clergeau, P. \& Mennechez, G., Biodiversity concepts and urban ecosystems. Landscape Urban Planning, 48(3-4), pp. 131-142, 2000.

[51] Dettmar, J., Ganser, K. \& Latz, P., IndustrieNatur: Ökologie und Gartenkunst im Emscher Park, Ulmer (Eugen), 1999. (In German.)

https://books.google.co.uk/books?id=FmPTAAAACAAJ.

[52] Kowarik, I., Das besondere der städtischen flora und vegetation. Schriftenr des Dtsch Rates für Landespfl, 61, pp. 33-47, 1992. (In German.)

[53] Ward Thompson, C., Urban open space in the 21st century. Landscape Urban Planning, 60(2), pp. 59-72, 2002.

http://linkinghub.elsevier.com/retrieve/pii/S0169204602000592.

[54] Rupprecht, C.D.D. \& Byrne, J.A., Informal urban green-space: Comparison of quantity and characteristics in Brisbane, Australia and Sapporo, Japan. PLoS One, 9(6), e99784, 2014.

[55] Gong, B., Study on comprehensive evaluation method of urban remnant natural area and case application, Shanghai Jiao Tong University, 2007. (In Chinese.)

[56] Gong, B. \& Che, S., Diversified values of urban remnant natural area. Journal of Shanghai City Management Vocational and Technical College, 18(3), pp. 40-43, 2009. (In Chinese.)

[57] Wang, X., Urban interstitial space: Strategic research on the planning of wildscape in the context of living environment. Urban Development Studies, 24(7), pp. 11-16, 2017. (In Chinese.)

[58] Zheng, L., Research on the methodology of ecological planning and design for urban natural remnant area: The case of Great Green Island in Shanghai, Shanghai Jiao Tong University, 2007. (In Chinese.)

[59] Chen, W., Hao, P. \& Qi, J., Ecological landscapism on the horizon: Introducing wilderness into human landscape. Journal of Scottish Thought, 9, pp. 160-174, 2017.

[60] Han, F., The Chinese View of Nature: Tourism in China's Scenic and Historic Interest Areas, Queensland University of Technology, 2006.

[61] Liu, Y., Wang, L. \& Long, H., Spatio-temporal analysis of land-use conversion in the eastern coastal China during 1996-2005. Journal of Geographical Sciences, 18(3), pp. 274-282, 2008.

[62] Güneralp, B., Perlstein, A.S. \& Seto, K.C., Balancing urban growth and ecological conservation: A challenge for planning and governance in China. Ambio, 44(6), pp. 532-543, 2015.

[63] Liu, J. \& Diamond, J., China's environment in a globalizing world: How China and the rest of the world affect each other. Nature, 435(7046), pp. 1179-1186, 2005.

[64] Yang, X. \& Jiang, S., Challenges Towards Ecological Sustainability in China: An Interdisciplinary Perspective, Springer: Cham, 2019.

[65] Zheng, H. \& Cao, S., Threats to China's biodiversity by contradictions policy. Ambio, 44(1), pp. 23-33, 2014.

[66] Chen, G., Grumbine, R.E., Dao, Z., Sun, W. \& Guo, H., Conserving plant species with extremely small populations (PSESP) in China. Biodivers Conservation, 22, pp. 803809, 2013.

[67] Wang, X., Preface: Ecology speaks for itself. Landcape Architecture, pp. 1-2, 2018. (In Chinese.)

[68] Wang, X., Preamble: Urban wilderness and urban habitats. Landcape Architecture, 26(1), pp. 4-5, 2019. (In Chinese.) 
[69] Jin, Y., Fang, L. \& Shen, J., Place-making strategy of brownfield regeneration of industrial forests in Ruhr. Chinese Landscape Architecture, 34(6), pp. 70-74, 2018. (In Chinese.)

[70] Chen, W. \& He, P., "Industrial forest": A particular strategy for the management of brownfield - Case study of Ruhr and Shanghai. Chinese Landscape Architecture, 8 , pp. 115-119, 2015. (In Chinese.)

[71] Del Tredici, P., The flora of the future. Places Journal, 2014.

[72] Feng, S., Theory and Planning of Abandoned Mine Land Restoration Oriented by Urban GI: A Case Study of Xuzhou, Chinese University of Mining Technology, 2015. (In Chinese.)

[73] Feng, S., Hou, W. \& Chang, J., Changing coal mining brownfields into green infrastructure based on ecological potential assessment in Xuzhou, Eastern China. Sustainability, 11(8), pp. 1-13, 2019.

[74] Yang, S., The Comparative Research on the Post-Mining Landscape of the Artificial Recovery Area and Natural Recovery Area in Xuzhou, Chinese University of Mining and Technology, 2017. (In Chinese.)

[75] Tang, H., Research of the Coal Mining Sudsidence Area with High Groundwater in Plain Area-Taking Xuzhou Jiuli Lake Subsidence Area as Example, Nanjing University, 2011. (In Chinese.)

[76] Xu, J., Study on Land Ecological Evolution and Impact Assessment of a Typical Plain Coal Mining Area: A Case Study in Xuzhou Mining Area, China University of Mining and Technology, 2013. (In Chinese.)

[77] Yu, S., Study on the Spatial Evolution and Optimal Strategies of Coal-Mining Subsided Wetlands in Xuzhou, Chinese University of Mining Technology, 2017. (In Chinese.)

[78] International Union for Conservation of Nature and Natural Resources, The IUCN Red List of Threatened Species, 2016, 2016.

[79] Cui, Z., Qin, X., Si, Q. \& Cui, Y., The research on summer avian communities of the derelict Jiangwan Airport in Shanghai. Proceedings of Chinese Zoological Society of Animals, the 8th National Congress of the Chinese Zoological Society of Birds and the 6th Symposium on Cross-Strait Ornithology, 2005. (In Chinese.)

[80] Jin, X., Zhou, B., Qin, X., Cui, Z., Xia, J. \& Si, Q., The biodiversity of the derelict Jiangwan Airport in Shanghai. Proceedings of the Sixth National Symposium on Biodiversity Conservation and Sustainable Use, 2004. (In Chinese.)

[81] Yang, Y., Wang, J. \& Da, L., Diversity, spatial pattern and dynamics of vegetation under urbanization in Shanghai (II): Study on the flora of Jiangwan Airport, an abandoned land, Shanghai. Journal of East China Normal University, 4, pp. 40-48, 2008. (In Chinese.)

[82] Oriental Morning Post, Response to the shrinkage of Shanghai urban wetland, 2010. (In Chinese.) http://city.sina.com.cn/focus/t/2010-11-29/165311057.html. Accessed on: 17 Sep. 2019. 